\title{
Photo-oxidation behaviour of polyethylene/polyamide 6 blends filled with organomodified clay: Improvement of the photo-resistance through morphology modification
}

\author{
N.Tz. Dintcheva ${ }^{\mathrm{a}, *}$, G. Filippone ${ }^{\text {b }}$, F.P. La Mantia ${ }^{\mathrm{a}}$, D. Acierno ${ }^{\mathrm{b}}$ \\ ${ }^{a}$ Dipartimento di Ingegneria Chimica dei Processi e dei Materiali, Università di Palermo, Viale delle Scienze, Ed. 6, 90128 Palermo, Italy \\ ${ }^{\mathrm{b}}$ Dipartimento di Ingegneria dei Materiali e della Produzione, Università di Napoli Federico II, Piazzale V. Tecchio, 80, 80125 Napoli, Italy
}

\section{A R T I C L E I N F O}

\section{Article history:}

Received 17 November 2009

Accepted 24 December 2009

Available online 11 January 2010

Keywords:

Photo-oxidation behaviour

Nanocomposite polymer blends

Microstructure

Mechanical properties

\begin{abstract}
A B S T R A C T
The impact of small amounts of organomodified clay (OMMT) on the photo-degradation behaviour of two blends obtained by mixing either low-density polyethylene (LDPE) or high density polyethylene (HDPE) with polyamide 6 (PA6) (LDPE/PA6 and HDPE/PA6 75/25 wt-\%) was studied. The complex photodegradation behaviour was followed by monitoring the main physical-mechanical properties of the blends. In particular, mechanical and spectroscopic tests were performed in conditions of accelerated artificial aging. An accurate mechanical and morphological characterization was previously carried out. The presence of the OMMT promotes the unexpected formation of a co-continuous morphology for the HDPE/PA6 blend without significantly improving the interfacial adhesion. Differently, the OMMT-filled LDPE/PA6 blend exhibits a finely distributed morphology, and some apparent improvement of the interfacial adhesion was noticed. Probably due to these differences in microstructure, a different impact of the nanoparticles on the photo-resistance behaviours was observed for the two families of samples. In particular, the HDPE-based nanocomposite blend exhibits an improved photo-resistance, while the opposite occurs for the LDPE-based system.
\end{abstract}

Published by Elsevier Ltd.

\section{Introduction}

Polymer blends have gained much interest in the last years and are becoming more and more important because of the favourable balance of properties and cost. In order to obtain blends with enhanced properties, the opportune choice of the blend constituents and the control of the microstructure generated during mixing are strictly required $[1,2]$. Besides mixing different polymers, an alternative approach to improve the performances of polymeric materials foresees the addition of solid particles by melt compounding the constituents. As widely reported in the literature, using nano-sized particles allows reducing drastically the amount of filler required to improve technologically relevant properties with respect to the case of conventional micron-sized particles $[3,4]$. In the last years, several research groups have tried to use simultaneously the two previous approaches in order to produce nanocomposite polymer blends with improved performances. In particular, it has been observed that the uneven distribution of the nanoparticles in the polymer phases may result in unexpected

\footnotetext{
* Corresponding author. Tel.: +39 0916567204; fax: +39 0917025020

E-mail address: dintcheva@dicpm.unipa.it (N.Tz. Dintcheva).
}

increases of the mechanical and transport properties due to the synergism among the reinforcing action of the filler and the benefits deriving from the changes in the blends' microstructure, such as the refinement of the morphology, the enhancement of the interfacial adhesion and the possible formation of co-continuous morphologies [5-12].

Among the hundreds of immiscible polymer blends of technological interest, the attention of this research was focused on blends of polyethylene and polyamide, widely employed in a variety of packaging and automotive products because of their good processability, high barrier and mechanical properties. Polyethylene offers high impact strength resistance and a good barrier to humidity, while the polyamides have good mechanical properties and are a barrier to oxygen. Unfortunately, polyethylene and polyamide form incompatible blends and many properties are not as good as expected. In order to improve some macroscopic properties, the use of compatibilizer precursors is often required [7,13-15]. Recently, several paper available in the literature [8,10-12] have shown that the presence of small amounts of the organomodified nanoparticles is able to change the morphology and, consequently, the macroscopic properties of polyolefin/polyamide blends. In some cases, the clay enriches the interfacial region acting like a copolymer compatibiliser, thus enhancing the 
interfacial adhesion. Alternatively, the filler plays a significant role in promoting the formation of a co-continuous morphology from the droplet-matrix morphology of the unfilled blends.

In outdoor applications such as sheets for packaging and automotive products, it is peculiarly important to take care of the resistance to photo-oxidation. Exposure of polymers in their use conditions provokes photo-oxidation, which causes the decrease of their macroscopic properties due to the variation of molecular weight, chemical structure and the morphology [16-18]. As widely reported in the literature, the presence of the organomodified clay in the different homopolymers leads to accelerated thermo- and photo-degradation. Many causes of the accelerated degradation of the polymer/clay nanocomposites were suggested, such as a decomposition of the ammonium ions (it can lead to the formation of the catalytic acidic sites on the layers), a catalytic effect of the iron impurities, a generation of a supplement amount of radicals coming from the oxidation of the modifier alkyl chain and some migration of the polar antioxidant onto the clay, the latter effect being more pronounced for unmodified silicate [19-33]. The photo-oxidation of the polymer blends is an even more complex phenomenon, depending on many additional factors such as the co-existence of radicals coming from the blend constituents (i.e. the specific degradation ways of the blend constituents and uneven reaction between them), the deep penetration of UV radiation and the migration of oxygen into the sheet.

The objective of the present study is focused on the analysis of the impact of small amounts (5 wt-\%) of an organomodified montmorillonite on the photo-degradation behaviour of two blends obtained by mixing either low-density polyethylene (LDPE) or high density polyethylene (HDPE) with polyamide 6 (PA6) (LDPE/ PA6 and HDPE/PA6 75/25 wt-\%). In order to follow the photooxidation behaviour of both the unfilled and OMMT-filled systems, the blend sheets were exposed to UV light in condition of accelerate artificial aging. The photo-oxidation behaviour of all the sheets was monitored by mechanical tests and by spectroscopic FT-IR analyses. Before the artificial aging, accurate morphological and mechanical analyses were performed upon all the samples. The effect of the filler on the photo-oxidation behaviour results different for the two blends: the OMMT causes an improvement of photo-oxidation resistance in the HDPE-based system, while the opposite occurs for the LDPE-based systems. Such differences seem related to the different microstructures exhibited by the samples, as well as to the different degree of crystalline of the two polyethylene matrices.

\section{Experimental}

\subsection{Materials and blend preparation}

The two polyethylenes of our blends (both from Polimeri Europa, Italy), were a high density polyethylene (HDPE Eraclene ${ }^{\circledR}$ MP94), with density $\rho=0.96 \mathrm{~g} / \mathrm{cm}^{3}$ at $23^{\circ} \mathrm{C}$ and $\mathrm{MFI}_{190^{\circ}} \mathrm{C} / 2.16 \mathrm{~kg}$ of $7.0 \mathrm{~g} / 10^{\prime}$, and a low-density polyethylene (LDPE Riblene ${ }^{\circledR}$ FC30), with density

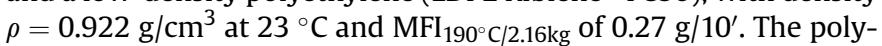
amide 6 (PA6 Radilon ${ }^{\circledR} \mathrm{S}$, supplied by Radici Group, Italy) has density $\rho=1.13 \mathrm{~g} / \mathrm{cm}^{3}$ and intrinsic viscosity $[\eta]=1.5 \mathrm{dL} / \mathrm{g}$ measured at $30^{\circ} \mathrm{C}$ in 80 vol-\% formic acid. An organomodified montmorillonite (Cloisite ${ }^{\circledR} 15 A$ from Southern Clay Products) was used to prepare the nanocomposite blends. Cloisite ${ }^{\circledR} 15 \mathrm{~A}$ is a montmorillonite modified by dimethyl-dihydrogenated tallow-quaternary ammonium cation with concentration of the organomodifier of $125 \mathrm{meq} / 100 \mathrm{~g}$ clay and density $\rho=1.66 \mathrm{~g} / \mathrm{cm}^{3}$. The designations and compositions of the samples are summarized in Table 1.

The nanocomposite blends were prepared in two steps: first, the organoclay was compounded with the polymeric constituents of the blends using a co-rotating intermeshing twin-screw extruder
Table 1

Blends' composition.

\begin{tabular}{ll}
\hline Sample & Composition [wt/wt + phr] \\
\hline LDPE/PA6 & $75 / 25$ \\
LDPE/PA6+OMMT & $75 / 25+5 \mathrm{phr}$ \\
HDPE/PA6 & $75 / 25$ \\
HDPE/PA6+OMMT & $75 / 25+5 \mathrm{phr}$ \\
\hline
\end{tabular}

(mod. OMC, Italy). The extrudate was cooled in water at the die exit, dried by air and then granulated. The thermal profile was $140^{\circ} \mathrm{C}$ $200^{\circ} \mathrm{C}-240^{\circ} \mathrm{C}-240^{\circ} \mathrm{C}-240^{\circ} \mathrm{C}-240^{\circ} \mathrm{C}-220^{\circ} \mathrm{C}$ and the screw speed was set to $\sim 100 \mathrm{rpm}$, corresponding to residence times of order of $\sim 150 \mathrm{~s}$. In order to produce sheets for the subsequent photooxidation analyses, the pellets were extruded again using a Brabender single screw extruder $(D=19 \mathrm{~mm}, \mathrm{~L} / \mathrm{D}=25)$ attached to a Brabender Plasticorder PLE 651 and equipped with a ribbon head. The thermal profile of this second extrusion step was $240-240-240^{\circ} \mathrm{C}$ and screw speed was $50 \mathrm{rpm}$. The thickness of the samples was $\sim 85 \mu \mathrm{m}$. The unfilled PE/PA blends were processed in the same processing conditions, i.e. the same processing temperatures and screw speeds.

\subsection{Characterization}

Wide-angle X-ray analyses (WAXD) were performed at room temperature in the reflection mode on a Siemens D-500 X-ray diffractometer with $\mathrm{Cu} \mathrm{K} \alpha$ radiation of wavelength of $0.1542 \mathrm{~nm}$. A scanning rate of $10{ }^{\circ} \mathrm{C} \mathrm{min}^{-1}$ was used. The distances $\mathrm{d}_{001}$ between the silicate layers of the organoclay in the nanocomposite blends was evaluated using the Bragg's condition $\mathrm{d}_{001}=\mathrm{n} \lambda /(2 \sin \theta)$, where $\lambda$ is the wavelength, $\theta$ is the angle in incidence of X-ray beam and $n$ is an integer.

The microstructure of the blends was inspected using a scanning electron microscope SEM Leica 420 . The observed cryo-fractured surfaces of the samples were previously coated with a thin layer of gold.

In order to quantify the extent of phase continuity of the PA6 phase in the blends, $\varphi_{\mathrm{PA}}$, quantitative extraction experiments were performed. For this aim, several samples were immersed into formic acid, a selective solvent for the polyamide, and the extraction process was protracted for about two weeks. The change in weight during extraction and the knowledge of the nominal composition of the samples lead to the estimation of $\varphi_{\text {PAG }}=\left(m_{0}-m_{f}\right) / m_{0}$, where $m_{0}$ and $m_{f}$ represent the nominal masses of PA6 in the blends before and after the experiments, respectively. All the samples, weighted after drying at $90{ }^{\circ} \mathrm{C}$ for $16 \mathrm{~h}$, remained selfsupporting after the extractions.

Mechanical tests were carried out according to ASTM test method D882 by using an Instron machine mod. 3365. The samples, stored for one week at room temperature and humidity, were tested at $1 \mathrm{~mm} / \mathrm{min}$ up to a strain of $10 \%$; then, the speed was increased up to $100 \mathrm{~mm} / \mathrm{min}$ until break. Young's modulus, tensile strength and elongation at break were recorded, and the data reported represent the average values obtained by analyzing the results of eight tests per sample; the variability of mechanical tests was typically of order of $\pm 5 \%$.

Fourier transform infra-red (FT-IR) spectra were evaluated using the Spectrum One Spectrometer by Perkin-Elmer and its Spectrum software. The spectra were obtained using 16 scans and a $4 \mathrm{~cm}^{-1}$ resolution. The variations of the carbonyl and hydroxyl band areas were determined from peak absorption area between 1850 and $1680 \mathrm{~cm}^{-1}$ and $3700-3300 \mathrm{~cm}^{-1}$, respectively. Moreover, the variation of peak area at $909 \mathrm{~cm}^{-1}$ was monitored (peak area 
between 980 and $950 \mathrm{~cm}^{-1}$ ). Measurements were obtained from the average of triplicate samples.

The attenuated total reflectance Fourier transform infra-red (ATR-FTIR) spectrometry was performed using an AutoImage FT-IR microscope Perkin Elmer equipped with a Micro-ATR objective. Spectra were collected using 32 scans per sample at a resolution of $4 \mathrm{~cm}^{-1}$.

Differential scanning calorimetry (DSC) was performed using a DSC60 Shimadzu. In order to erase any thermal history effects, the samples were heated from $25^{\circ} \mathrm{C}$ to $300^{\circ} \mathrm{C}$, kept for 2 min at $300^{\circ} \mathrm{C}$, cooled down to $25^{\circ} \mathrm{C}$, and then heated again up to $300^{\circ} \mathrm{C}$. The data presented refer to the second heating scans. The heating and cooling cycles were all carried out at $20{ }^{\circ} \mathrm{C} \mathrm{min}^{-1}$ under nitrogen atmosphere.

The artificial accelerated photo-oxidation tests were performed using a Q-UV chamber mounting eight UV-B lamps. The weathering conditions, in the presence of oxygen, were $8 \mathrm{~h}$ of light at $T=55^{\circ} \mathrm{C}$ and $4 \mathrm{~h}$ of condensation at $T=35^{\circ} \mathrm{C}$.

\section{Results and discussion}

Our previous analysis on OMMT-filled PE/PA6 blends [10,12,15] shows that the organoclay locates preferentially inside the more hydrophobic polyamide phase. A small clay quantity, difficult to quantify, is located between the two polymeric phases and contributes to modify the size and shape of the filled PA6 phase. We think that the uneven distribution of the nanofiller represents the key factor for the changes in morphology and properties variations of the OMMT-filled PE/PA blends.

The SEM micrographs of the unfilled and OMMT-filled blends are shown in Fig. 1. As expected on the basis of the incompatibility between the polymer components, the two unfilled blends show the typical globular morphology of immiscible blends, with spherical droplets of the minor PA6 phase suspended in the LDPE (Fig. 1 (a)) or HDPE (Fig. 1 (b)) matrix. In addition, the micro-voids surrounding the PA6 droplets indicate that the interfacial adhesion is weak for both the samples. The OMMT radically affects the
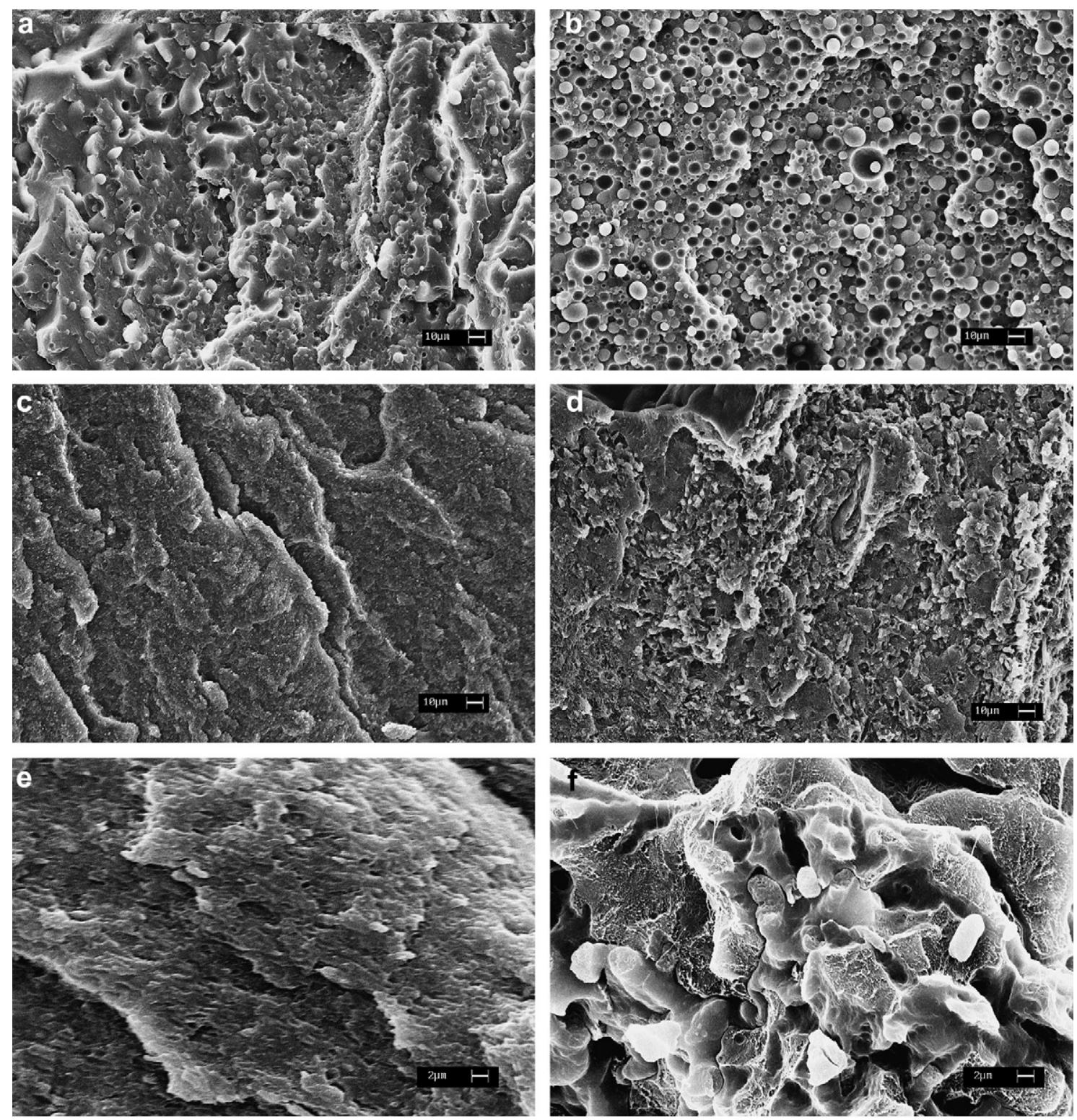

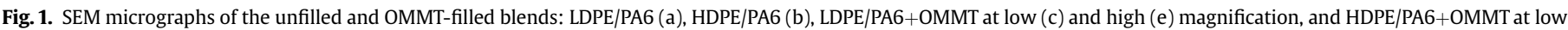
(d) and high (f) magnification. 
Table 2

Degree of continuity of the PA6 phase as estimated through quantitative extraction experiments.

\begin{tabular}{ll}
\hline Sample & $\varphi_{\text {PA6 }}[\%]$ \\
\hline LDPE/PA6 & 21.7 \\
LDPE/PA6+OMMT & 22.5 \\
HDPE/PA6 & 22.8 \\
HDPE/PA6+OMMT & 87.3 \\
\hline
\end{tabular}

morphology of both nanocomposite blends, promoting a drastic refinement of the morphology, which is particular evident for the LDPE-based blend (Fig. 1 (c and d)). Although the irregular surface of the two samples makes difficult to discern clearly the polymer phases, a visual inspection of the SEM micrographs at higher magnification shown in Fig. 1 (b) and (d) show a substantial differences between the two samples: the OMMT seems promoting a better interfacial adhesion in the LDPE-based sample (Fig. 1 (e)); on the contrary, the polymer phases of the HDPE-based sample remain separated and the OMMT mainly affects the shape of the minor PA6 phase, which result highly irregular (Fig. 1 (f)). Such observation is in agreement with the results of quantitative extraction experiments, which are summarized in Table 2.

The polyamide phase of the OMMT-filled HDPE/PA6 blend exhibits a considerable extent of phase continuity, meaning that its irregular shape promoted by the filler results in a high degree of interpenetration of the phases. Differently, the extent of extractable PA6 phase of the LDPE-based nanocomposite blend remains essentially unaltered.

In order to assess the into the nanocomposite blends, X-ray diffratometry was performed. The interlayer distances $\mathrm{d}_{001}$ for the OMMT-filled HDPE/PA6 and LDPE/PA6 system are $3.48 \mathrm{~nm}$ and $3.28 \mathrm{~nm}$, respectively. The two nanocomposite blends show interlayer distances slightly higher than that of the unprocessed OMMT, which $\mathrm{d}_{001}$ is $3.14 \mathrm{~nm}$. This means that the organoclay results slightly intercalated in both the filled systems. It is interesting to remark that the results of WAXD analyses are in quite good agreement with those of the ATR-FTIR investigations. This kind of analysis, representing an innovative technique to monitor the state of dispersion of the layered clays, was applied to the OMMT-filled sheets' surface, and the results are reported in Fig. 2 (a).
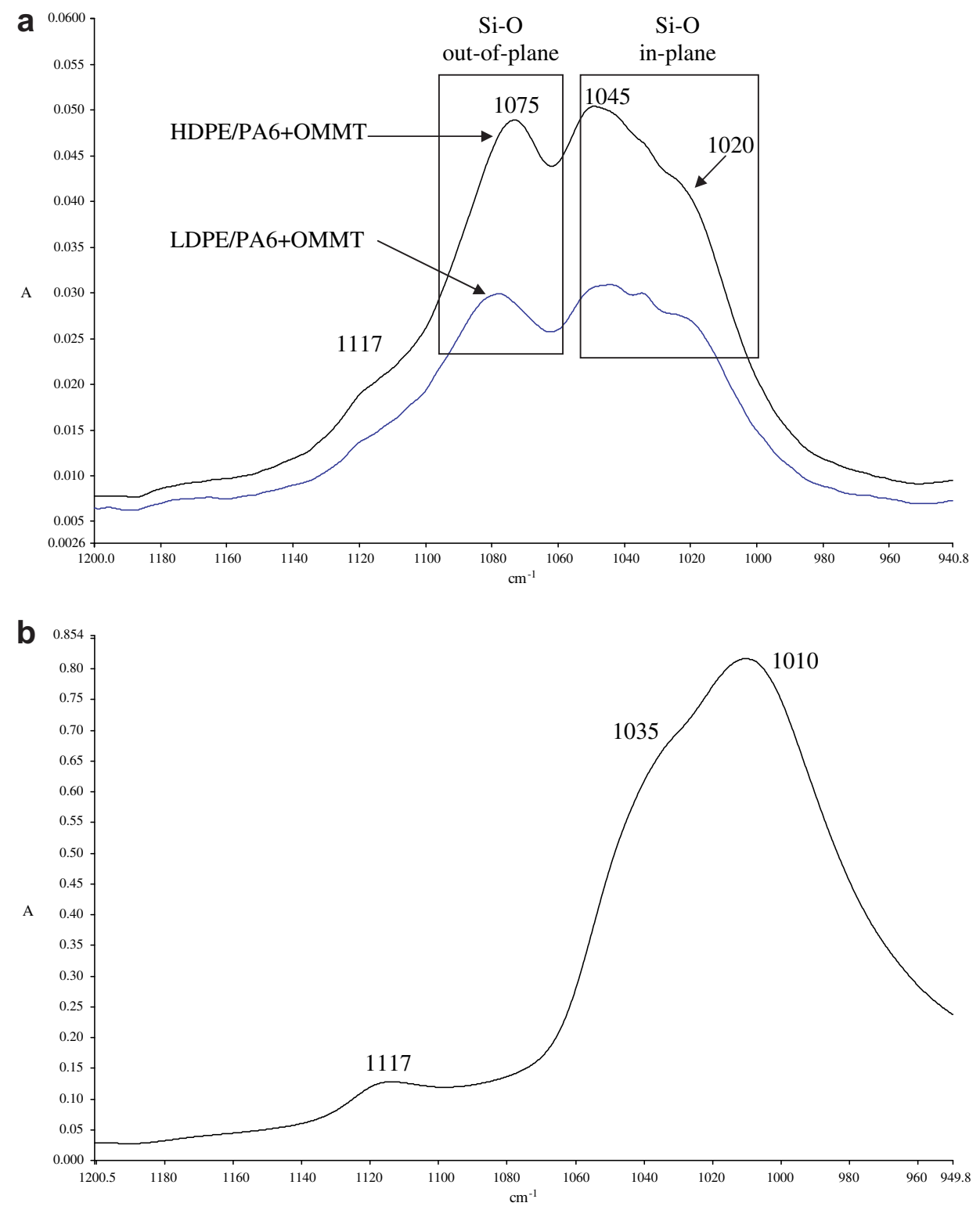

Fig. 2. ATR-FTIR spectra of the OMMT-filled blends (a) and of the pristine OMMT (b). 


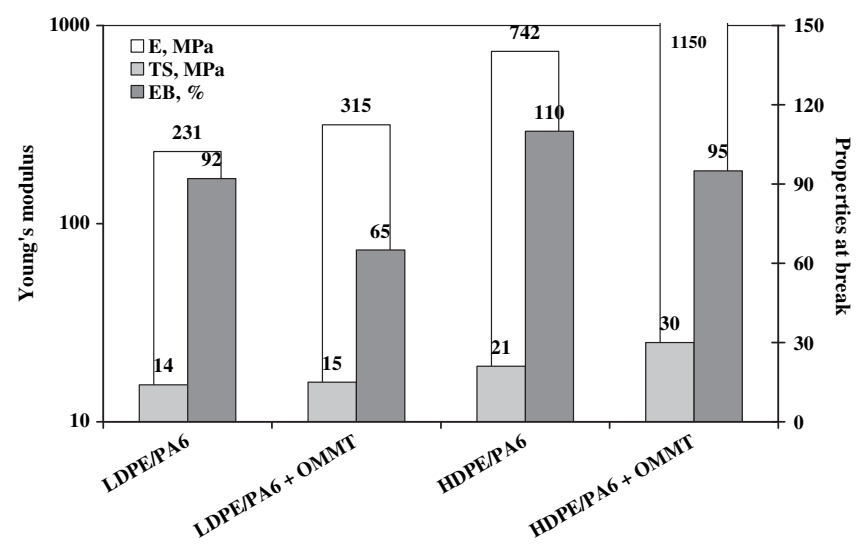

Fig. 3. Young's modulus, E, (left axis), tensile strength, TS, and elongation at break, EB, (right axis) of the unfilled and OMMT-filled PE/PA blend systems.

As known in the literature [32,34], the pristine clay shows one broad band in the region $950-1150 \mathrm{~cm}^{-1}$ (see Fig. 3(b)), while the splitting of the $v(\mathrm{Si}-\mathrm{O})$ bands, i.e. the individuation of the different distinct peaks at around 1020,1045, 1075 and $1171 \mathrm{~cm}^{-1}$, indicates the formation of the delimited clay structures. This ATR-FTIR technique was successfully applied in both cases of aqueous clay dispersion [35] and of solid polyethylene nanocomposite sheets [33]. The formations of more resolved peaks, corresponding to the in-plane and out-of-plane $\mathrm{Si}-\mathrm{O}$ absorptions, in OMMT-filled PE/PA6 blends are in agreement with the results of the WAXD analysis. The grade of the peak resolution at 1045 and $1075 \mathrm{~cm}^{-1}$, indicates the level of the layer delaminating and dispersion.
Furthermore, the results about the clay dispersion in the two OMMT-filled PE/PA6 blends are similar but better dispersion of the HDPE-based sample, in agreement with WAXD results, was obtained.

The effect of the OMMT on the mechanical properties of the blends is shown in Fig. 3, where the Young's modulus, tensile strength and elongation at break are reported.

It is evident that the presence of OMMT significantly increases the values of the Young's modulus for the nanocomposite blends. Such increases are about $+35 \%$ and $+55 \%$ for the LDPE-based and HDPE-based systems, respectively. Concerning the properties at break, it can be noticed that the tensile strength in the presence of the OMMT of the LDPE-based blend remains essentially unchanged, while an increase of TS was noticed for the HDPE-based blend. In addition, both the blends exhibit a comparable reduction of the elongation at break due to the presence of the OMMT. Such results are not unexpected, as the tensile strength of polymer blends/ organoclay typically results unaffected or slightly higher with respect to the unfilled systems, while the elongation at break of polymer blend/organoclay systems significantly decreases [6-10].

The previous analyses highlight the fundamental role of the OMMT in promoting remarkable changes in the morphology and, as a consequence, in the mechanical properties of the studied blends. In particular, besides refining drastically the microstructure of both blends, the OMMT enhances the interfacial adhesion in the LDPEbased system, probably enriching the interfacial region, and promotes a high degree of continuity of the PA6 phase in the HDPEbased sample. A rough representation of the impact of the OMMT on the morphology of the studied blends is reported in Fig. 4.

In the light of the previous remarks, the photo-oxidation behaviour of unfilled and OMMT-filled blends has been studied.
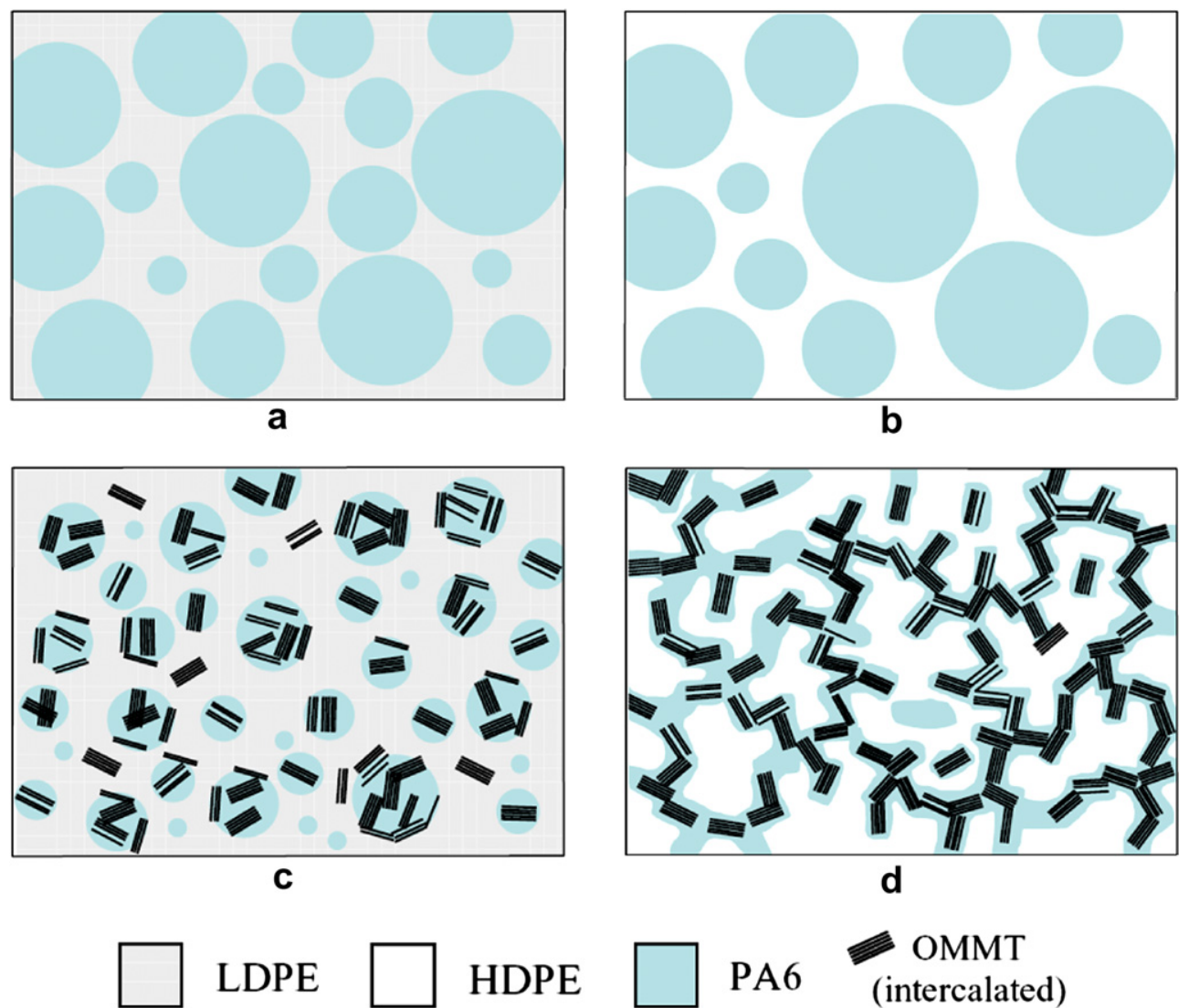

Fig. 4. Schematic representation of the blends' morphology: LDPE/PA6 (a), HDPE/PA6 (b), LDPE/PA6 + OMMT at low (c) and HDPE/PA6 + OMMT (d). 


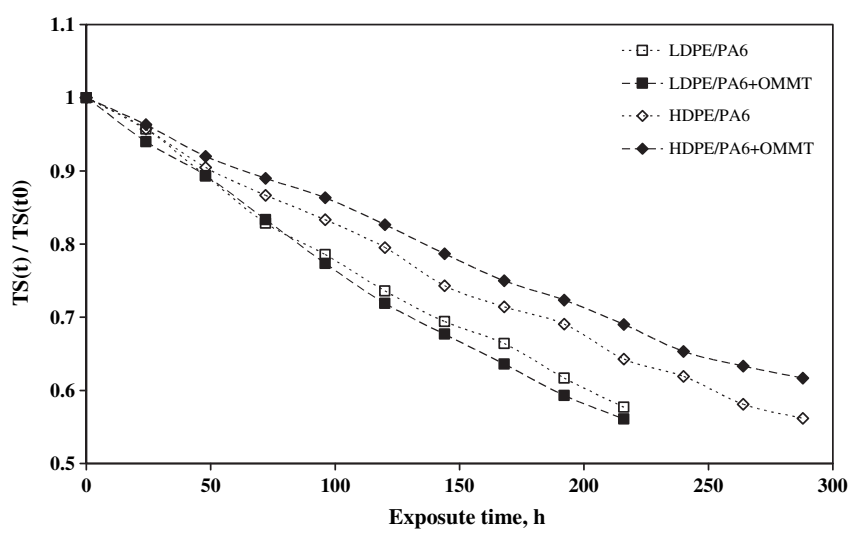

Fig. 5. Tensile strength as a function of the exposure time of the unfilled and OMMTfilled blends.

The photo-oxidation behaviour of all the samples has been followed by means of mechanical tests and FT-IR analysis.

In Figs. 5 and 6, the trend of the dimensionless tensile strength and elongation at break is reported as a function of the exposure time. The dimensionless properties are calculated by dividing the values of TS and EB at different exposure times by the values of unexposed material. The properties at break, in particular the elongation at break, were used to follow the photo-oxidation behaviour because of their sensitivity to the structural and morphological variations of the materials occurring during the

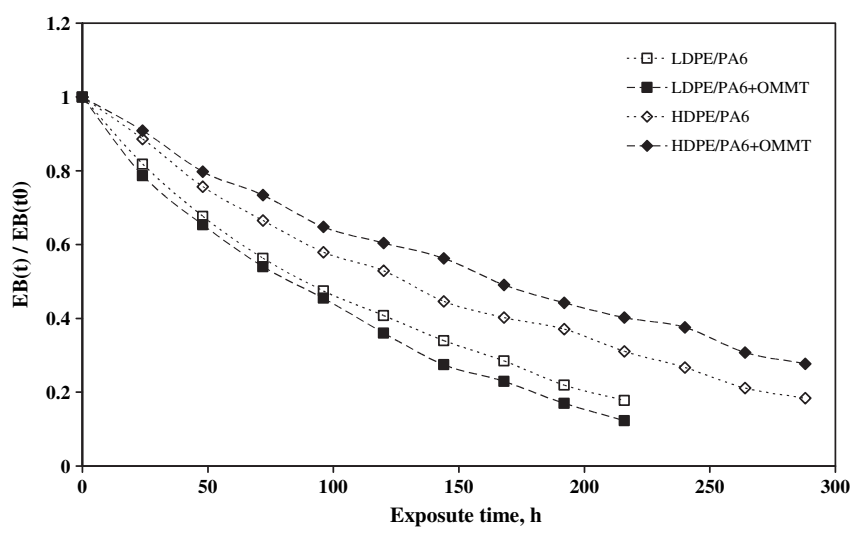

Fig. 6. Elongation at break as a function of the exposure time of the unfilled and OMMT-filled blends.

photo-oxidation. The curves of the dimensionless TS and EB of LDPE-based unfilled and OMMT-filled blends are quite similar, but the decay of the properties at break is accelerated in the presence of the organoclay. In addition, both unfilled and OMMT-filled LDPE-based blends show comparable half-time of elongation at break, i.e. the time at which EB is one half of its initial value. On the contrary, the OMMT slows down the photo-oxidation process for the HDPE-based sample, and the half-time of elongation at break of the nanocomposite blend increases of about 30\%. Such an enhancement of the photo-oxidation resistance is quite surprising,
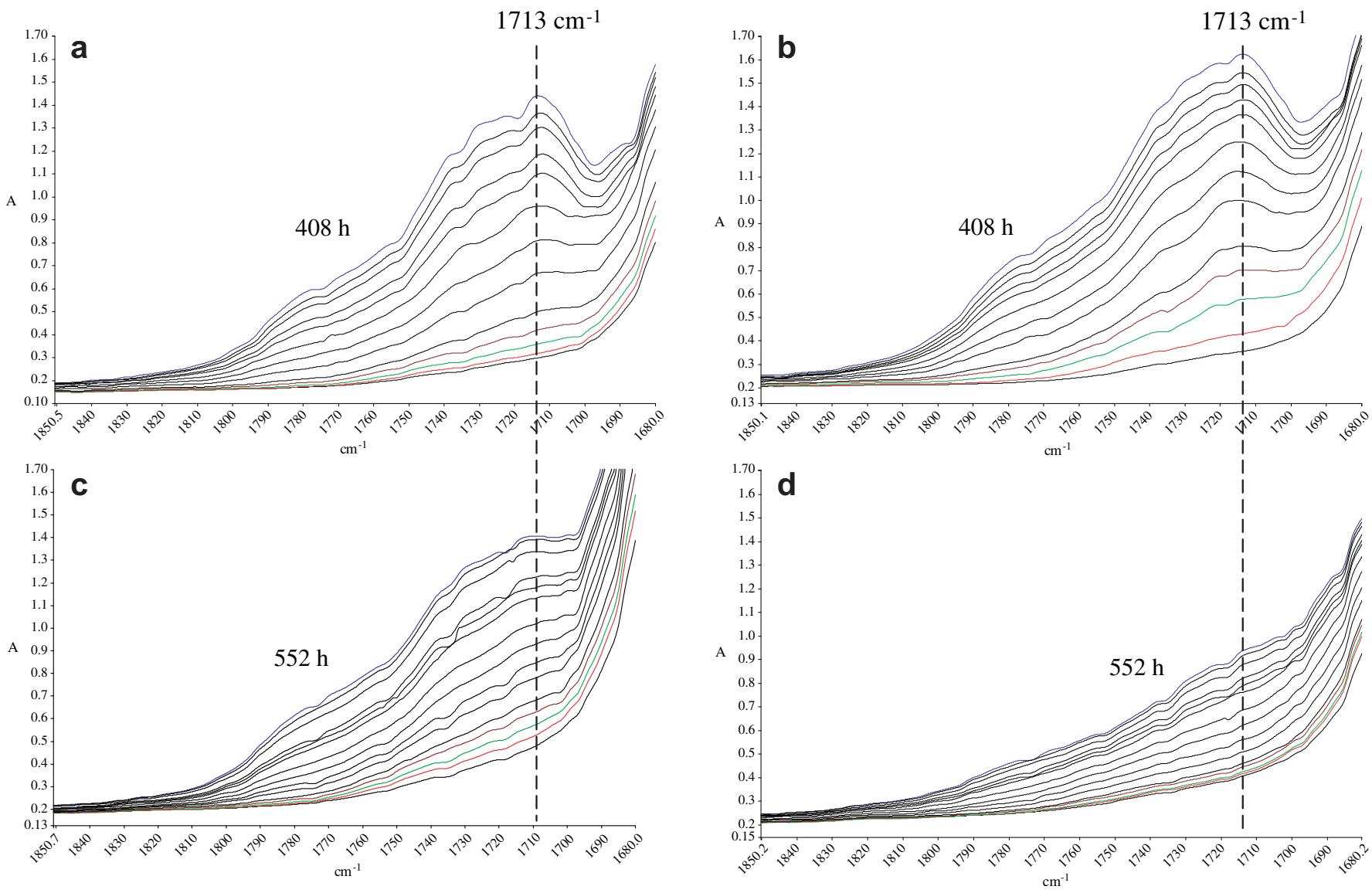

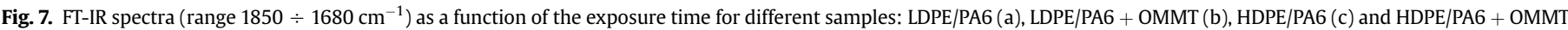
(d). The last spectra of each sample corresponding of the spectra at maximum indicated exposure time. 
since the presence of organomodified clay either in polyethylene or polyamide generally brings about a significant reduction of the photo-oxidation resistance [19-33].

Besides monitoring of the mechanical properties during the exposure time, the photo-oxidation behaviour of all the blends was followed by means of FT-IR analysis. The FT-IR spectra at increased exposure times are reported in Figs. 7-9. Actually, the artificial exposure to the UV light was extended to times longer than in the case of the mechanical tests because in the latter case the samples get too brittle and, therefore, the results of mechanical tests become poorly reproducible. The peak areas at different ranges, in particular the areas of carbonyl, hydroxyl and peak area at $909 \mathrm{~cm}^{-1}$, were evaluated as a function of the exposure time and the results are shown in Figs. 10-12. The trends of the carbonyl formation and hydroxyl formations follow the same trends as the properties at break, and the differences between the different unfilled and OMMT-filled systems get more marked with increasing the exposure time.

It is interesting to highlight that the formation of unsaturated groups for the unfilled and OMMT-filled LDPE/PA6 blends, which can be followed by monitoring the variation of the peak area at $909 \mathrm{~cm}^{-1}$, is higher than that of the HDPE-based blends; as a matter of fact, the vinyl unsaturated formation of these samples is not relevant.

Based on the indications emerged from microstructural analyses, several hypotheses can be proposed in order to explain the differences between the LDPE- and HDPE-based systems. As reported in the literature $[38,39]$, we argue that the photo-oxidation reactions start in the polyamide phase and then the polyamide
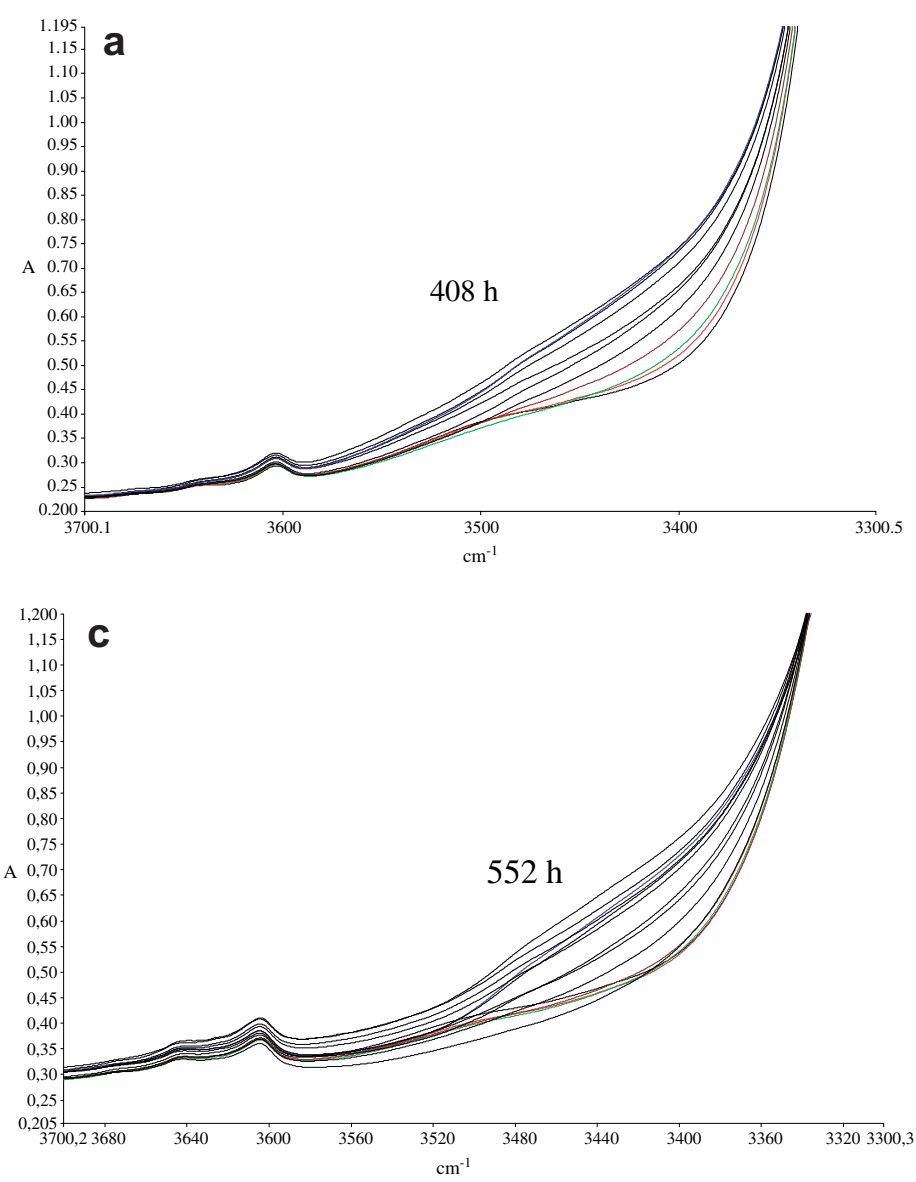

radicals promote the degradation in the polyethylene. The diffusion process of the radicals is hindered by the crystallites, so that differential calorimetric analysis was performed in order to assess the degree of crystallinity of the polymer phases of each blend. The results of DSC carried out before and after the exposure to the artificial aging are summarized in Table 3.

Before the photo-oxidation, the presence of the OMMT has comparable effects on both the LDPE- and HDPE-based samples. In particular, the presence of OMMT does not affect the melting temperature, $\mathrm{T}_{\mathrm{m}}$, and enthalpy, $\Delta \mathrm{H}_{\mathrm{m}}$, of the polyolefin phases. Conversely, a slight decrease of $\Delta \mathrm{H}_{\mathrm{m}}$ can be noticed for the polyamide, suggesting that the organoclay located in this phase partially hinders the crystallization. Moreover, the OMMT promotes the formation of a $\gamma$-form crystalline fraction for the PA6 $\left(T_{\mathrm{m}} \approx 214{ }^{\circ} \mathrm{C}\right)$ in addition to the usual $\alpha$-form $\left(T_{\mathrm{m}} \approx 221{ }^{\circ} \mathrm{C}\right)$. This phenomenon has been already reported in the literature for PA6-based nanocomposites [10,36,37].

Irrespective of the presence of the filler, the higher photoresistance exhibited by the HDPE-based blends with respect to the LDPE-based samples could be due to the higher crystallinity degree of the HDPE, which impedes the propagation of the radicals in the major polyethylene phase decreasing the photo-oxidation rate. Nevertheless, the opposite effect of the OMMT on the two series of blends is more difficult to explain. After the photo-degradation, a comparable increase of the melting enthalpies of the polymer phases occurs for all the samples, suggesting that the effect of the OMMT on the degree of crystallinity is not responsible for the different impact of the filler on the photo-oxidation behaviour exhibited by the two nanocomposite blends. In particular, the lower
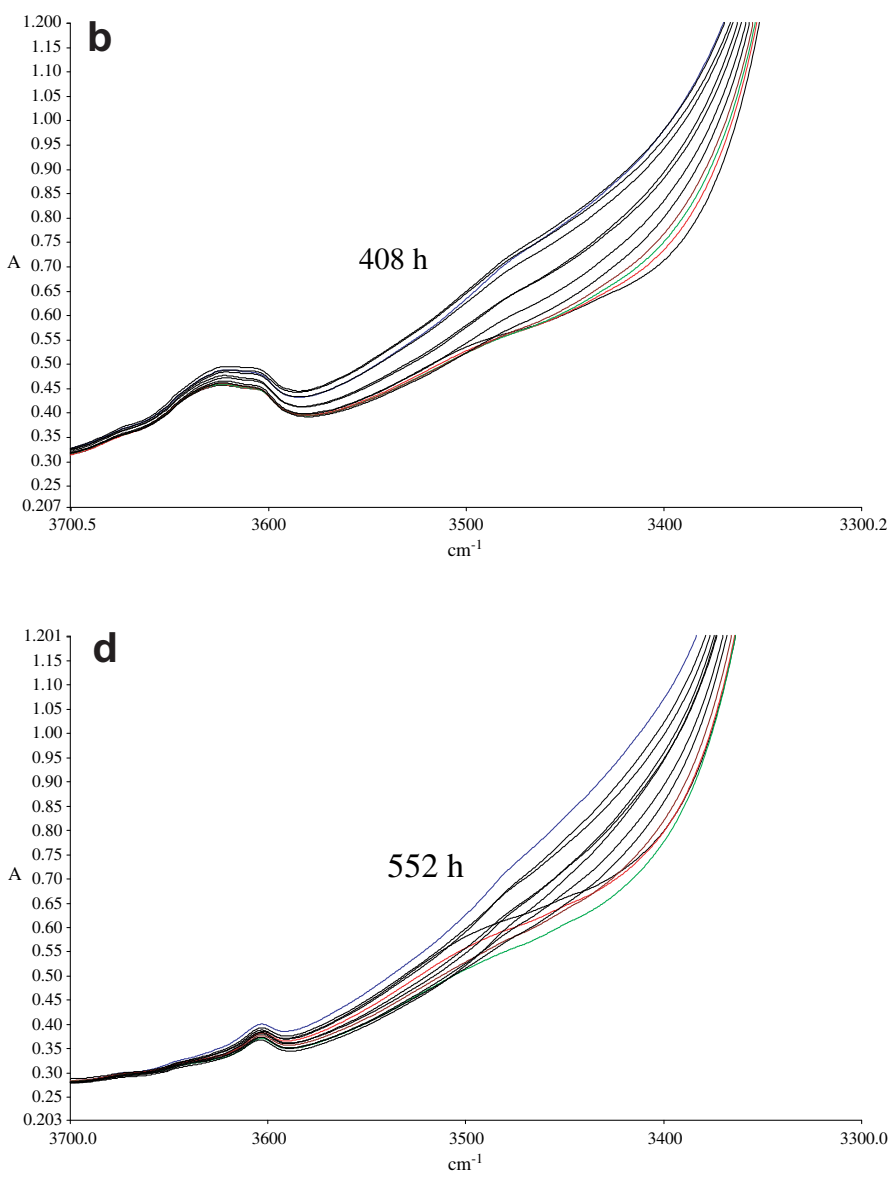

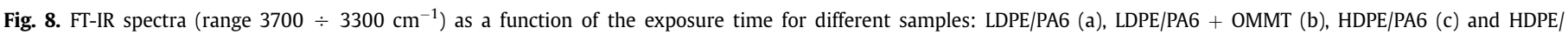
PA6 + OMMT (d). The last spectra of each sample corresponding of the spectra at maximum indicated exposure time. 

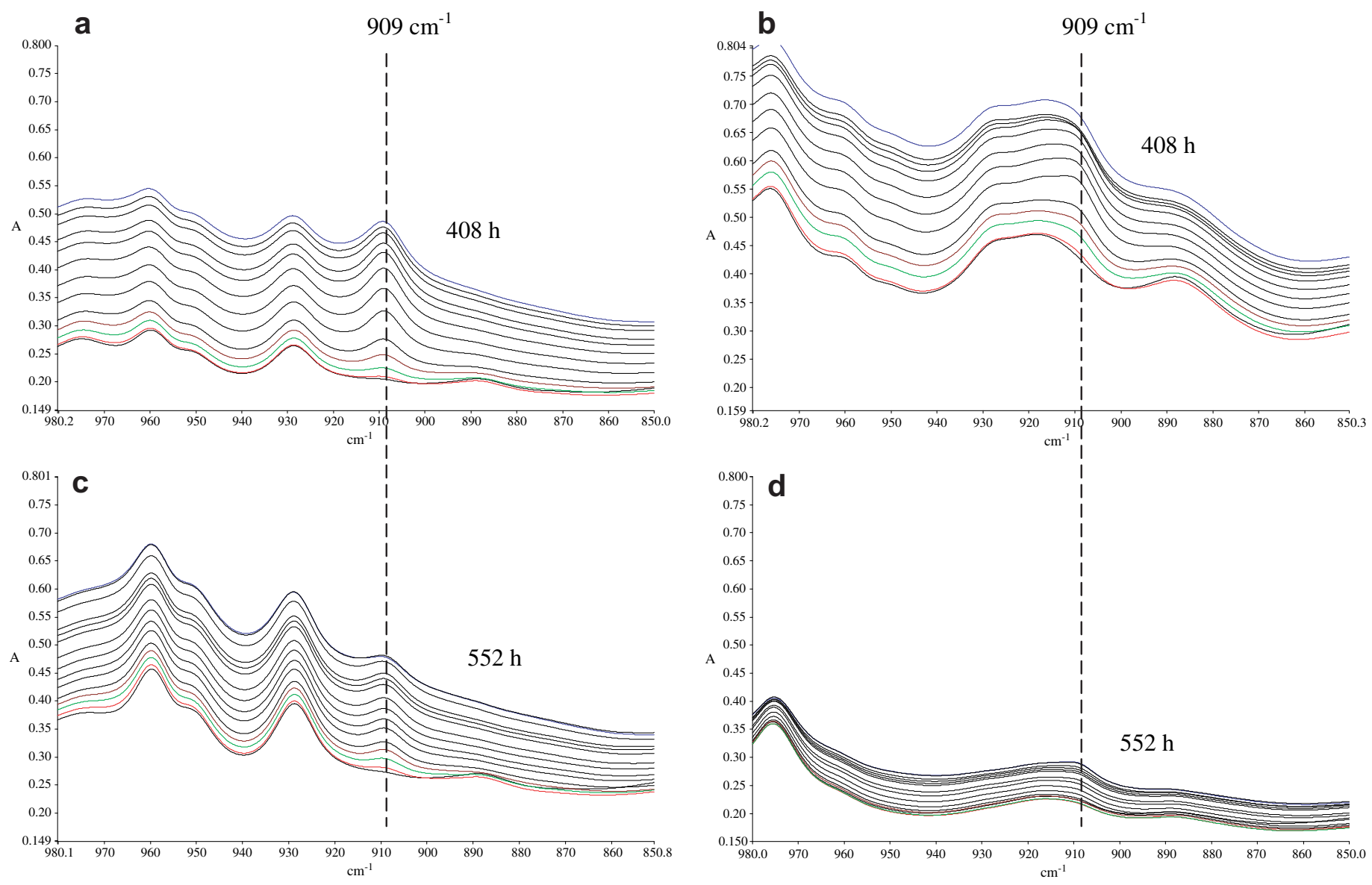

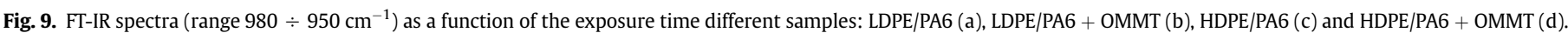
The last spectra of each sample corresponding of the spectra at maximum indicated exposure time.

resistance of the OMMT-filled LDPE-PA6 blend could be explained by considering that the $\mathrm{Fe}++$ ions, presented in layer of the phyllosilicates, exhibit their photo-pro(degradant) effect and the time at filled polymers show significantly reduced photo-oxidation induction time. On the other hand, the improved photo-oxidation resistance of OMMT-filled HDPE/PA6 blend cannot be explained by eluding its complex microstructure. In particular, the worse interfacial adhesion and lower specific interfacial area compared with the LDPE-based sample could play a role in slowing down the

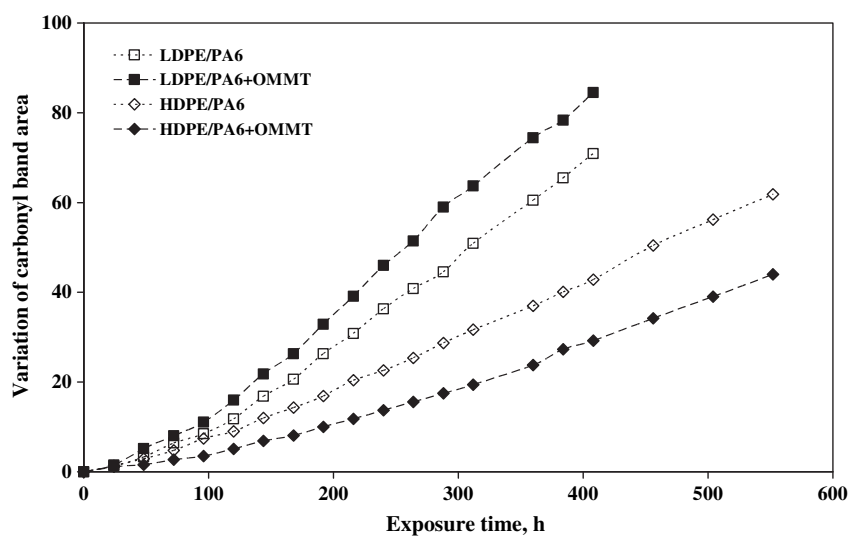

Fig. 10. Variation of the carbonyl band area as a function of the exposure time of the unfilled and OMMT-filled blends. propagation of the polyamide radicals toward the HDPE phase. In addition, the specific co-continuous morphology could contribute to improve the efficiency of the nanoparticles in contrasting the diffusion of the radicals, thus reducing the photo-oxidation rate. Although our experimental data clearly show the crucial role of the microstructure in enhancing the photo-oxidation resistance of nanocomposite polymer blends, discerning which one of the proposed mechanism may be the main responsible for the improvement observed for the OMMT-filled HDPE/PA6 blend is

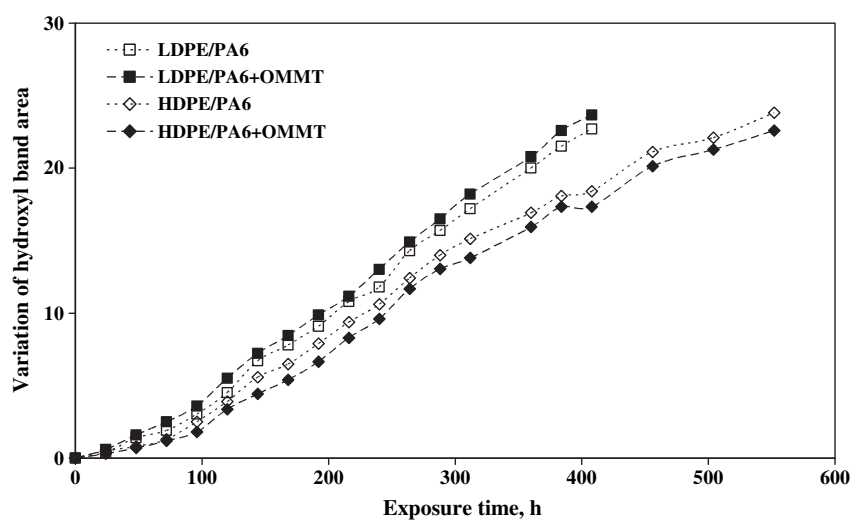

Fig. 11. Variation of the hydroxyl band area as a function of the exposure time of the unfilled and OMMT-filled blends. 


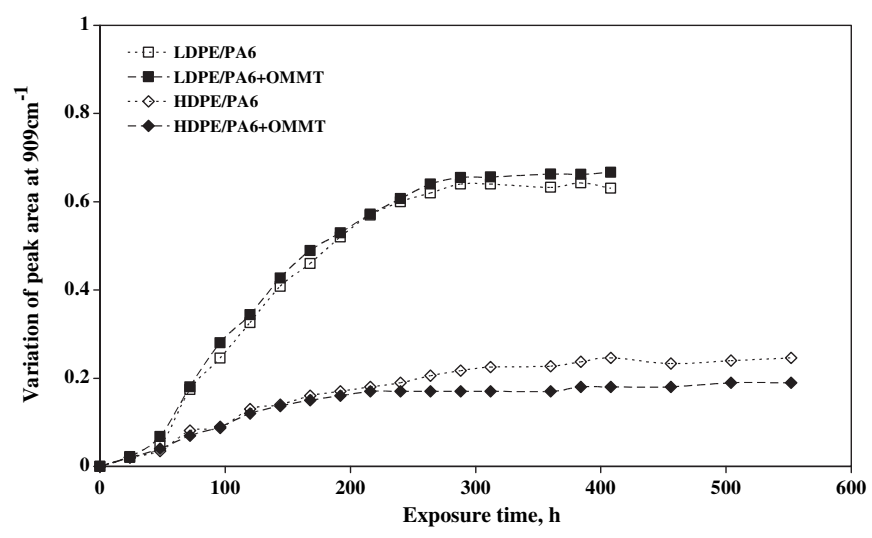

Fig. 12. Variation of peak area at $909 \mathrm{~cm}^{-1}$ as a function of the exposure time of the unfilled and OMMT-filled blends.

Table 3

Melting temperatures $\left(\mathrm{T}_{\mathrm{m}}\right)$ and enthalpies $\left(\Delta \mathrm{H}_{\mathrm{m}}\right)$ of unfilled and OMMT-filled blends before (a) and after (b) exposure to UV light.

\begin{tabular}{|c|c|c|c|c|}
\hline & \multicolumn{2}{|c|}{ PE peak } & \multicolumn{2}{|c|}{ PA peak(s) } \\
\hline & $\mathrm{T}_{\mathrm{m}},{ }^{\circ} \mathrm{C}$ & $\Delta \mathrm{H}_{\mathrm{m}}, \mathrm{J} / \mathrm{g}$ & $\mathrm{T}_{\mathrm{m}},{ }^{\circ} \mathrm{C}$ & $\Delta \mathrm{H}_{\mathrm{m}}, \mathrm{J} / \mathrm{g}$ \\
\hline \multicolumn{5}{|l|}{ (a) Before exposure } \\
\hline LDPE/PA6 & 109 & 55 & 221 & $7.7^{\mathrm{a}}$ \\
\hline LDPE/PA6/OMMT & 109 & 53 & $222 ; 214$ & $6.8^{\mathrm{b}}$ \\
\hline HDPE/PA6 & 135 & 105 & 221 & $6.9^{\mathrm{a}}$ \\
\hline HDPE/PA6/OMMT & 135 & 104 & $222 ; 214$ & $5.7^{\mathrm{b}}$ \\
\hline \multicolumn{5}{|l|}{ (b) At maximum exposure time } \\
\hline LDPE/PA6 (408 h) & 109 & 65 & 221 & $8.8^{\mathrm{a}}$ \\
\hline LDPE/PA6/OMMT (408 h) & 109 & 68 & $222 ; 214$ & $7.9^{\mathrm{a}}$ \\
\hline HDPE/PA6 (552 h) & 135 & 123 & 221 & $7.6^{\mathrm{a}}$ \\
\hline HDPE/PA6/OMMT (552 h) & 135 & 120 & $222 ; 214$ & $6.4^{\mathrm{a}}$ \\
\hline
\end{tabular}

a Predominant $\alpha$-form peak.

b Co-existence of both $\alpha$ - and $\gamma$-form.

difficult and it would require a targeted analysis, which is beyond the scope of the present work.

\section{Conclusions}

The photo-oxidation behaviour of unfilled and OMMT-filled polyethylene/polyamide blends was studied and the structural and physico-mechanical properties were monitored. An accurate characterization before the accelerated aging reveals a drastic impact of the organoclay on the morphology of the nanocomposite blends. In particular, the formation of a co-continuous morphology in the HDPE-based blend was observed, while an improvement of interfacial adhesion was noticed for the LDPE-based sample.

Due to the higher degree of crystallinity of the HDPE phase, the unfilled and OMMT-filled HDPE/PA6 blends show higher photo-resistance than the LDPE-based blends with respect to the accelerated UV-B aging. Mechanical test and FT-IR analysis indicate that the presence of the OMMT results in an accelerated photo-oxidation degradation for the LDPE-based system. On the contrary, the organoclay improves the photo-oxidation resistance of the HDPE/PA6 blend. This could be explained in the light of the complex microstructure exhibited by this sample, which poor interfacial adhesion and low specific interfacial area could hinder the propagation of the surfactant degradation products of the organoclay and the diffusion of polyamide radicals into the polyethylene phase.

\section{Acknowledgement}

This work has been financially supported by University of Palermo RS ex-60\% (ORPA07XR52: Comportamento foto-ossidativo di sistemi multi-componenti a base polimerica).

\section{References}

[1] Harrats Ch, Thomas S, Groeninckx G, editors. Micro- and nanostructured multiphase polymer blned systems. Taylor \& Francis, Boca Raton FL: CRC Press; 2006. p. 698.

[2] Jarus D, Hiltner A, Baer E. Polymer 2002;43:2401.

[3] Usuki A, Kojima Y, Kawasumi M, Okada A, Fukushima Y, Kurauchi T, et al. J Mat Res 1993;8:1179-84.

[4] Jordan J, Jacob KI, Tannenbaum R, Sharaf MA, Jasiuk I. Mat Sci Eng A-Struct 2005;393:1-11.

[5] Peng G, Qiu F, Ginzburg VV, Jasnow D, Balazs AC. Science 2000;288(5472): 1802-4.

[6] Wang S, Hu Y, Wang Z, Yong T, Chen Z, Fan W. Polym Degrad Stab 2003;80:157.

[7] Chow WS, Abu Bakar A, Mohd Ishak ZA, Karger-Kocsis J, Ishiaku US. Europ Polym J 2005;41:687-96.

[8] Chow WS, Mohd Ishak ZA, Karger-Kocsis J. Macromol Mater Eng 2005;290: 122-7.

[9] Lee MH, Dan CH, Kim JH, Cha J, Kim S, Hwang Y, et al. Polymer 2006;47:4359.

[10] Filippone G, Dintcheva NTz, Acierno D, La Mantia FP. Polymer 2008;49: $1312-22$.

[11] Fenouillot F, Cassagnau P, Majesté JC. Polymer 2009;50:1333-50.

[12] Filippone G, Dintcheva NTz, Acierno D, La Mantia FP. Effect of organoclay on the morphology and mechanical properties of LDPE/PA11 blends with distributed and co-continuous morphology. J Polym Sci Part B: Polym Phys, in press.

[13] Utracki LA. Commercial polymer blends. London: Chapman and Hall; 1998.

[14] Filippi S, Minkova L, Dintcheva NTz, Narducci P, Magagnini PL. Polymer 2005;46:8054-61.

[15] Filippi S, Dintcheva NTz, Scaffaro R, La Mantia FP, Polacco G, Magagnini PL. Polym Eng Sci 2009;49:1187-97.

[16] Ranby B, Rabek JK, editors. Photodegradation, photo-oxidation and photostabilisation of polymers. Wiley; 1975.

[17] La Mantia FP, Gardette JL. Polym Degrad Stab 2002;75:1-7.

[18] La Mantia FP, Dintcheva NTz. Plastic, Rubber and Composites 2004;33:184-6.

[19] Tidjani A, Wilkie CA. Polym Degrad Stab 2001;74:33-7.

[20] Qin H, Zhao C, Zhang Z, Chen G, Yang M. Polym Degrad Stab 2003;81: 497-500.

[21] Qin H, Zhang Z, Feng M, Gong F, Zhang S, Yang M. J Polym Sci Part B Polym Phys 2004;42:3006-12.

[22] Mailhot B, Morlat S, Gardette JL, Boucard S, Duchet J, Gerard JF. Polym Degrad Stab 2003:82:163-7.

[23] Davis RD, Gilman JW, Vander Hart DL. Polym Degrad Stab 2003;79:111-21

[24] Fornes TD, Paul DR. Macromoleculs 2004;37:7698-709.

[25] Shah RK, Paul DR. Polymer 2006;47:4075-84.

[26] La Mantia FP, Dintcheva NTz, Malatesta V, Pagani F. Polym Degrad Stab 2006;91:3208-13.

[27] Bocchini S, Morlat-Therias S, Gardette JL, Camino G. Polym Degrad Stab 2007;92:1847-56.

[28] NTz Dintcheva, La Mantia FP. Macromol Mater Eng 2007;292:855-62.

[29] Morlat-Therias S, Fanton E, Gardette JL, Dintcheva NTz, La Mantia FP, Malatesta V. Polym Degrad Stab 2008;93:1776-80.

[30] Botta L, Dintcheva NTz, La Mantia FP. Polym Degrad Stab 2009;94:712-8.

[31] Kiliaris P, Papaspyrides CD, Pfaendner R. Polym Degrad Stab 2009;94:389-96.

[32] Bottino FA, Di Pasquale G, Fabbri E, Orestano A, Pollicino A. Polym Degrad Stab 2009;94:369-74.

[33] NTz Dintcheva, Al-Malaika S, La Mantia FP. Polym Degrad Stab 2009;94: $1571-88$.

[34] La Mantia FP, Dintcheva NTz, Filippone G, Acierno D. J Appl Polym Sci 2006;102:4749-58.

[35] Johnston CT, Premachandra GS. Langmuir 2001;17:3712-8.

[36] Lincoln DM, Vaia RA, Wang Z-G, Hsiao BS, Krishnamoorti R. Polymer 2001;42: 9975.

[37] Bureau MN, Denault J, Cole KC, Enright GD. Polym Eng Sci 2002;42(9):1897.

[38] Nocilla MA, La Mantia FP. Polym Deg Stab 1990;29:331-9.

[39] Therias S, Dintcheva NTz, Gardette J-L, La Mantia FP. Photooxidative behaviour of polyethylene/polyamide-6 polymer blends. Polym Degrad Stab 2010;95: 522-6. 